\title{
PRÁTICAS DISCURSIVAS SOBRE/DA EDUCAÇÃO SEXUAL NA DITADURA MILITAR NO BRASIL
}

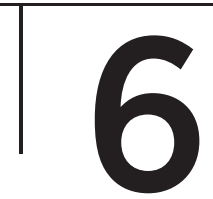

\section{PRÁCTICAS DISCURSIVAS SOBRE/ \\ DESDE LA EDUCACIÓN SEXUAL EN LA DICTADURA MILITAR EN BRASIL}

\section{MONTEIRO, Solange Aparecida de Souza}

Doutoranda em Educação Escolar na Universidade Estadual Paulista (UNESP), Araraquara/SP _ Brasil.

Pedagoga no Instituto Federal de Educação Ciência e Tecnologia de São Paulo (IFSP), Araraquara/ SP - Brasil.

Mestra em Processos de Ensino, Aprendizagem e Inovação.

E-mail: solmonteiro@ifsp.edu.br

ORCID: <http://orcid.org/0000-0002-1640-0266>

\section{RIBEIRO, Paulo Rennes Marçal}

Docente do Programa de Pós-Gradução em Educação Sexual e no Programa de Pós-Graduação em Educação Escolar na Universidade Estadual Paulista (UNESP), Araraquara/SP - Brasil.

E-mail: paulo.rennes@unesp.br

ORCID: <http://orcid.org/0000-0002-1552-5702>

\section{RESUMO:}

O presente artigo tem como principal objetivo refletir acerca das práticas discursivas oficiais, ou seja, quais são saberes sobre/da Educação Sexual brasileira circulantes no período da ditadura militar. Trata-se de pensar sobre os diferentes discursos em sua historicidade, enquanto processo de construção discursiva do sujeito e de sua sexualidade, os quais se instituíram em torno dessa educação em um período de repressão, impregnado pelo ideário moralista e autoritário. As práticas discursivas circulantes no âmbito educacional, em especial no recorte temporal analisado, tiveram como escopo fundante o discurso oficial do Ministério da Educação - especificamente a Lei de Diretrizes e Bases da Educação 5692/1971. Nesse discurso fundador houve a ausência de posicionamento de uma política de formação sexual escolar para a Educação Básica, que acabou por não gerar regulamentação nas escolas.

Palavras-chave: Educação Sexual no Brasil; ditadura militar; práticas discursivas. 


\section{ABSTRACT:}

El objetivo principal de este artículo es reflexionar sobre las prácticas discursivas oficiales, es decir, cuáles son el conocimiento sobre/de la educación sexual brasileña que circula en el período de la dictadura militar. Se trata de pensar en los diferentes discursos de su historicidad, como un proceso de construcción discursiva del tema y de su sexualidad, que se instituyeron en torno a esta educación en un período de represión, impregnado por la idea moralista y Autoritario. Las prácticas discursivas que circulan en el ámbito educativo, especialmente en el recorte temporal analizado, fueron el alcance fundacional del discurso oficial del Ministerio de Educación, específicamente la ley de directrices y bases de la educación 5692/1971. En este discurso fundacional se encuentra la falta de posicionamiento de una política de educación sexual escolar para la educación básica, que finalmente no generó regulación en las escuelas.

Keywords: Educación Sexual en Brasil; dictadura militar; prácticas discursivas.

\section{INTRODUÇÃO}

Educação Sexual e ditadura aparentemente são dois temas dessincronizados. No entanto, a confluência de diversos fatores, sendo um deles, o esforço coletivo e a preocupação comum de diversos pesquisadores que, cada um na sua área e à sua maneira, buscam compreender as complexas relações existentes entre esses dois temas nos fazem perceber a existência de uma educação sexual que esteve sob.

O controle da educação básica no país pelo regime militar, o qual não se deu apenas em forma de perseguição contra professores com história pessoal de militância. Também não se limitou à criação as disciplinas OSPB (Organização Social e Política Brasileira) e Educação Moral e Cívica, trazidas pela ditadura com o decreto-lei número 869, de 12 de setembro de 1969, que tornou Moral e Cívica obrigatória nas escolas de todos os níveis e, naquelas de $2^{\circ}$ grau, também OSPB. A tentativa de controlar a educação básica veio também em forma de censura ao conteúdo ensinado, aos livros adotados, aos termos que podiam ser ditos em relação aos vários temas e problemas, sendo assim o controle muitas vezes pode ser observado claramente e outras esse controle dissolviam-se sob a forma de ordem discursiva. 
Essa ordem discursiva não pertencia só ao âmbito escolar, mas a toda a sociedade. O quê dizer, como dizer, o direito de dizer deveria estar dentro da ordem discursiva estabelecida pelo regime da ditadura que controlava a circulação dos discursos. Por exemplo, debater sobre a sexualidade feminina era um temática censurada dentro da sociedade em geral, não só pela Igreja, mas também pela sociedade conservadora brasileira que não admitia essa discussão por entenderem que era algo promíscuo que atentava contra a moral e os bons costumes, até mesmo as organizações de esquerda e as próprias militantes refutavam debater sobre a sexualidade feminina mantendo as discussões apenas sob o viés político (COLLING, 2015).

Assim, qualquer tipo de prática educativa estava submetida a ordem discursiva estabelecida pelo modo de pensar da ditadura da época, todos temiam as sanções e exclusões imputadas aos sujeitos caso saíssem da ordem discursiva estabelecida.

Um dos espaços propícios para exercer o estabelecimento da ordem discursiva de uma determinada sociedade em um determinado tempo histórico é o espaço escolar. Foucault (1988) aponta a escola como um dos espaços que cumprem o papel de controle e normatização sobre os indivíduos e suas práticas sociais. O autor observou um discurso em que coexistem o papel de objeto, submetido à ação da natureza, e de sujeito, capaz de apreender o mundo e modificá-lo.

Mas o filósofo negou a possibilidade dessa convivência. Segundo ele, há apenas sujeitos, que variam de uma época para outra ou de um lugar para outro, dependendo de suas interações. Para Foucault (1988), a concepção do homem como objeto foi necessária na emergência e manutenção da Idade Moderna, porque dá às instituições a possibilidade de modificar o corpo e a mente. Entre essas instituições inclui-se a educação.

O conceito definidor da modernidade, segundo o autor, é a disciplina, um instrumento de dominação e controle destinado a suprimir ou domesticar os comportamentos divergentes. Portanto, ao mesmo tempo em que o iluminismo consolidou um grande número de instituições de assistência e proteção aos cidadãos, como família, hospitais, prisões e escolas, também inseriu nelas mecanismos que os controlam e os mantêm na iminência da punição. Veiga- Neto (2005), aponta que as sociedades modernas não são disciplinadas, 
mas disciplinares: o que não significa que todos nós estejamos igual e irremediavelmente presos às disciplinas.

Em Microfísica do Poder, Foucault entende que a dominação e o poder não sejam originários de uma única fonte como o Estado ou as classes dominantes, mas que são exercidos em várias direções, cotidianamente, em escala múltipla. Esse exercício também não era necessariamente opressor, podendo estar a serviço, por exemplo, da criação. Foucault via na dinâmica entre diversas instituições e ideias uma teia complexa, uma rede, formada pelo que denominou de micropoderes, em que não se pode falar do conhecimento como causa ou efeito de outros fenômenos. Para dar conta dessa complexidade, o pensador criou o conceito de poder-conhecimento. Os saberes especialmente acerca da sexualidade são compostos por diversos discursos, sendo a escola um espaço de constituição e divulgação bastante específico.

Os discursos escolares sobre sexualidade são, portanto, dotados de peculiaridade. Há uma linguagem própria para a comunicação dos temas sexuais. Igualmente, existe uma abordagem particular e um tipo especial de saber a ser transmitido, pois em se tratando de questões consideradas problemáticas que se relacionam à moralidade, nem tudo é permitido às instituições escolares. Os aspectos abordáveis no ambiente escolar se configuram historicamente, bem como a forma de lidar com eles. Portanto, as mais diversas sociedades e em diferentes temporalidades, estabelecem critérios para definir o que pode ser dito em termos de sexualidade. Assim, podemos afirmar que, em relação constante com os processos históricos e seus contextos sociais, culturais, discursos são construídos sobre e para a Educação Sexual, os quais devem obedecer a uma certa ordem discursiva em dado momento histórico.

Suponho que em toda sociedade a produção do discurso é ao mesmo tempo controlada, selecionada, organizada e redistribuída por certo número de procedimentos que tem por função conjurar seus poderes e perigos, dominar seu acontecimento aleatório, esquivar sua pesada e temível materialidade (FOUCAULT, 1996, p. 8.).

Em especial, as práticas discursivas da/sobre a sexualidade no âmbito escolar entram nesse controle da produção discursiva. Ao observar esses discursos em relação à historicidade as construções 
discursivas em torno da sexualidade das novas gerações, pode-se considerar que no olhar sobre a história, o importante é perceber que existe uma relação entre a forma como a identidade e o sujeito são representado dentro do movimento cultural, social e político da construção dos saberes de sua(s) representação (ões).

Para Furlani (2008, p. 287), a Educação Sexual sempre se constituiu numa questão polêmica no espaço escolar, e por largo tempo os currículos escolares mantiveram-se distantes dessa discussão explicitamente. Por isso, é possível pensar nela como um campo de conhecimento em que, historicamente, tem prevalecido o conveniente silenciamento, a estratégica restrição temática, o privilegiamento do senso comum, a manutenção do preconceito e da intolerância, a possível falta de preparo pedagógico das(os) educadoras(es) e o sutil descaso por parte da Escola e das políticas educacionais. Louro (1999, p. 129-130), ao se referir aos anos 1960, argumenta que:

Para muitas pessoas esse período é considerado fundamental no âmbito das relações de gênero e sexuais, seja porque percebem ali o início de uma era de "permissividade", seja porque o identificam com a "revolução sexual", seja porque registram um incremento na "mercantilização do sexo", ou ainda porque observam grandes mudanças nas formas de "regulação da sexualidade" - com a crescente referência à homossexualidade, ao aborto, à pornografia etc.

Essas transformações e demandas sociais se refletem nos currículos escolares de todas as épocas. Guimarães (1995), quando apresenta um histórico da educação no Brasil, aponta que sempre houve inúmeras iniciativas de instituir oficialmente o ensino da Educação Sexual. Essas iniciativas estiveram presentes em todas as décadas. As transformações culturais da década de 1960, ao discutir temas específicos de interesse na época: prazer, métodos contraceptivos (pílulas), gravidez, ISTs, aborto etc. O descontinuíssimo histórico tocou de forma profunda o desenvolvimento de diretrizes de educação sexual no Brasil.

As práticas discursivas sobre/da sexualidade no âmbito escolar no período ditadura advinham de lugares estabelecidos como os responsáveis para tratarem disso, tais como o discurso médico, biológico, familiar. À escola cabia ordená-los, reproduzi-los de acordo com os modos de pensar e de dizer vigentes na época, em especial tratá-los sob uma perspectiva biologizante. Nesse sentido, não era 
proibido falar sobre sexualidade, mas o que se controlava era o modo como se falava de tal tema.

\section{A EDUCAÇÃO SEXUAL E A LEGISLAÇÃO EDUCACIONAL}

A partir do processo de reformulação curricular, instituído por meio da LDB (Lei 9.394/96), a Educação Sexual foi admitida como de responsabilidade da escola e passou a ser incorporada oficial e legalmente nos currículos por meio dos chamados temas transversais, propostos nos Parâmetros Curriculares Nacionais: Mary del Priore (2011, p. 126), aborda que, no Brasil, a partir das primeiras décadas do século XX, começaram a ocorrer as tentativas de conscientização sobre a necessidade da Educação Sexual para jovens. Com ela, a política governamental lançou, a partir do ano de 1997, os Parâmetros Curriculares Nacionais (PCNs), além de ética, saúde, pluralidade cultural, meio ambiente e estudos econômicos, pela primeira vez, de maneira visível, na chamada questão transversal "orientação sexual", de modo que a educação sexual nunca esteve longe da escola, o ponto principal que deve ser considerado refere-se ao conjunto de condições a que esse tipo de educação, ou seja, foi possível estabelecer como Educação Sexual nos mais diversos contextos históricos.

Ao contrário daquilo que se habituou a pensar sobre o discurso pedagógico, a respeito da ocultação sobre o sexo e das práticas sexuais, desde o final do século XIX, o sexo já era objeto de discussões entre médicos e educadores que defendiam a presença de uma educação para a higiene sexual dos jovens.

O Circulo Brasileiro de Educação Sexual - CBES criou o Boletim de Educação Sexual, que circulou entre 1933 e 1939, fundado na cidade do Rio de Janeiro, então capital federal, o CBES foi uma entidade de características filantrópicas que possuía como objetivo promover uma reforma sobre a educação/cultura sexual da população brasileira, com atuação ampla e intensa, desenvolveu uma campanha pela educação sexual com as mais variadas atividades, entre palestras, conferências, semanas de educação sexual, posto de atendimento gratuito sobre higiene e psicologia sexual chegando a constituir o 'Circuito Jornalístico' do CBES, com a filiação de 700 jornais que publicavam quinzenalmente artigos sobre o assunto.

O campo discursivo dos intelectuais na área da Educação Sexual, nas primeiras décadas do século XX no Brasil, tem como uma de suas 
preocupações centrais o controle dos corpos, a partir do domínio da energia sexual e da normalização das relações entre homens e mulheres. Para alguns educadores meninos e meninas deveriam receber informações sobre o sexualismo; para outros, porém, só os meninos deveriam ser instruídos, já que a eles caberia a maior responsabilidade para com a família. Obviamente, essa prática discursiva assentava-se no saber estabelecido pela sociedade do momento que determinava os papéis cabíveis às mulheres (espaço privado, dona de casa, cuidar dos filhos, afazeres domésticos) e aos homens (espaço público, mundo do trabalho, político, administração dos bens, etc.). Logo, a sociedade dos anos 1960 entendia o lugar de discussão da sexualidade como o espaço do íntimo, ou seja, dentro do âmbito familiar.

Embora, o discurso oficial não contemplasse a Educação Sexual formal dentro da escola, as demandas por esse tema ocorriam naturalmente, e de sob um currículo oculto essa educação exercia-se sob outra roupagem, mas de forma controlada e cerceada fosse pelo medo de dizer, fosse pela insegurança de como abordá-la, ou fosse pela falta de recursos didáticos pedagógicos para ensiná-la.

Portanto, constata-se que a sexualidade era compreendida por grande parte da sociedade como um assunto anti-higiênico, antipedagógico e imoral. Devido a isso muitos professores optaram por não abordar este assunto, por temerem represálias e intimidações. Em consequência, no final da década de 1960 há um certo recuo em matéria de orientação sexual na escola.

Werebe (1977) afirma que na realidade os anos 1960 constituíramse um momento favorável à implantação da Educação Sexual no Brasil. Guimarães (1995) corrobora que nesta década surgem algumas tentativas de implantação da Educação Sexual no Brasil nas escolas públicas e particulares nos estados de São Paulo, Rio de Janeiro e Minas Gerais.

No que concerne a essas tentativas pioneiras do século passado, na cidade de São Paulo, tais iniciativas ocorreram no contexto de algumas escolas que experimentavam uma proposta de renovação pedagógica. Tais iniciativas não sobreviveram ao agravamento do autoritarismo do país, que assumiu uma postura nitidamente moralista (ROSEMBERG, 1985).

Em 1963 no Estado de Minas Gerais o Grupo Escolar Barão do Rio Branco introduziu esta orientação para alunos da oitava série do 
ensino fundamental, porém a experiência durou apenas três anos devido à reação negativa dos pais. Já no Rio de Janeiro, o colégio André Maurois após alguns anos de inserção da Educação Sexual, passou por uma crise em 1968.

Por outro lado, temos a Educação Sexual tomada sob o viés biologizante, controlada, apesar de na prática discursiva tentar mostrar-se favorável a ser realizada para meninos e meninas, podemos observar que Padilha, (1997, p. 432). declarou-se favorável, em todos os outros pontos de Educação Sexual de meninos e meninas, sejam feitas em conjunto, pois se um dos objetivos, instruindo-os nas coisas da reprodução, é conservá-los puros! Se os separarmos por sexos para tais aulas, fatalmente estabeleceremos a maldade, quando assim não deve ser; devem habituar-se a ouvir com naturalidade, pois o inocente não cora; só o maldoso se sente envergonhado diante da ciência. Kehl (1997), apesar de ser favorável a que garotos e garotas recebessem educação sexual, considera que "Convém que as lições sejam separadamente para os meninos e para as meninas, e adaptadas ao interesse dos respectivos sexos. O sucesso do ensino depende sempre do tato e da habilidade do mestre" (KEHL, 1997, p. 436).

A Educação Sexual também esteve sob a égide do discurso lúdico, em que o tema é tratado com leveza tornando-o visível, mas não há reflexão sobre o mesmo e a aceitação do diferente ainda é uma questão complexa. Green (2014, p. 19) aponta que, neste momento, verificam-se mudanças importantes na sociedade LGBT no Brasil. Do ponto de vista da diversão e do entretenimento, surgiram boates e casas noturnas, no Rio de Janeiro e em São Paulo, dirigidas especialmente para um público homossexual. Passou a haver maior visibilidade dos espaços públicos frequentados por gays e lésbicas nos principais centros urbanos. Alguns homens começaram a transformar seus corpos com hormônios e se intensificou a presença de travestis nas grandes cidades fora da época do carnaval. Aconteceu, ainda, certa, abertura nos meios culturais e intelectuais para uma visão mais tolerante à homossexualidade.

César (2008), em oposição a essas ideias que se estabeleceram no imaginário a respeito da ocultação sobre o sexo e as práticas sexuais, desde o final do século XVIII e, notadamente, desde o século XIX, o sexo já era objeto de discussões entre médicos e educadores que defendiam a presença de uma educação para a higiene sexual 
dos jovens. Estas primeiras tentativas do século XX em defesa da educação sexual nas escolas brasileiras manifestavam-se por meio de pressupostos higienistas e eugênicos, ou seja, as práticas discursivas sobre/da sexualidade circulantes dentro da escola continuavam sob o controle dos saberes médico e biológico. Sob essa perspectiva as identidades sexuais são construídas por meio de discursos que, por sua vez, representam um processo de relações desiguais de poder. Por outro lado, não há como negar que ao se constituírem histórica e socialmente os papéis sexuais, são estabelecidos os critérios de pertencimento identitário aos sujeitos, mas também os critérios de exclusão.

A prática discursiva da diversidade ainda tem um longo e duro caminho que vem sendo percorrido pela população LGBT (Lésbicas, Gays, Bissexuais, Travestis, Transexuais e Transgênero), garantir os direitos e respeito à diversidade sexual e de gênero. No entanto, é somente nas últimas décadas do século $X X$ que se reconhece a especificidade de cada uma das múltiplas identidades que compõem essas siglas permanentemente variáveis. Não foi até a década de 1990 que essas diferenciações começaram a ser reconhecidas. Antes disso, todos os segmentos da população LGBT eram ignorados e geralmente descritos e estigmatizados como tendo uma "lacuna" ou "anomalia". Até meados do século $\mathrm{XX}$, a homossexualidade era tratada em todo o mundo como um ataque aos valores religiosos, como um problema médico ou até mesmo um problema policial. As reações da sociedade ao comportamento homossexual incluem: tratamento psiquiátrico, aprisionamento e perseguição policial nas ruas. No entanto, esta opressão tem gradualmente levado a ações de resistência por indivíduos que começaram a formas uma identidade LGBT e a defender direitos como uma categoria particular.

Nos anos 1980, o discurso jurídico entra em cena para normatizar o que deve ser ou não ser aceito, o que são os direitos específicos dos homossexuais. Esses direitos foram objeto de intensos debates na Assembleia Nacional Constituinte, de 1988. No entanto, as conquistas legais do movimento foram e são bem menores que as obtidas por outros grupos de excluídos, como quilombolas e indígenas, entre outros.

Em relação à superação da discriminação, por exemplo, há a manutenção da prática discursiva da educação sexual sob o viés 
biológico e o silenciamento do discurso do heterogêneo, pois a Constituição limitou-se a equiparar os direitos e deveres entre homens e mulheres, fundamentando-se no sexo e ignorando as distinções de gênero e a orientação sexual. Sob o pretexto de proteger a família, a sociedade, seus valores e sua moral, a questão LGBT foi praticamente excluída do texto, em uma votação na Assembleia Constituinte. A Carta Constitucional somente determina, genericamente, que deve ser promovido: "o bem de todos, sem preconceitos de origem, raça, sexo, cor, idade e quaisquer outras formas de discriminação". Mesmo assim, o certo é que as grandes manifestações de rua promovidas por homossexuais, nas últimas décadas, serviram de base para importantes transformações e conquistas da comunidade LGBTs junto ao Estado brasileiro.

A maioria dessas conquistas se deu por atuação do Poder Judiciário e, entre elas, se destacam: A realização da cirurgia para mudança de sexo pelo Sistema Único de Saúde (SUS) nos hospitais públicos dos Estados; A permissão da adoção de crianças por casais homoafetivos; $\mathrm{O}$ direito de servidores públicos federais, travestis ou transexuais, de usarem o nome social (pelo qual preferem ser chamados e pelo qual se reconhecem) em cadastros dos órgãos em que trabalham; O direito de homossexuais de incluírem o companheiro, ou a companheira, como dependente na declaração do Imposto de Renda; O direito de homossexuais de receberem pensão do INSS pela morte de seus cônjuges; $\mathrm{O}$ registro das uniões estáveis e casamento civil de casais homoafetivos; Direito e benefícios aos cônjuges de militares homossexuais idênticos aos de casais heterossexuais; Benefício de licença-maternidade a pais adotivos que vivem em união estável homossexual; Reconhecimento jurídico da união estável e direito a partilha de bens entre pessoas do mesmo sexo, conforme ADPF 132 (Ação de descumprimento de Preceito Fundamental $n^{\circ} 132$ ) e ADI 4277 (Ação Direta de Inconstitucionalidade $n^{\circ} 4277$ ), julgadas em maio de 2011 pelo Supremo Tribunal Federal (STF), que estendem todos os direitos garantidos às uniões heterossexuais também para as homossexuais. O aparelho repressivo criado pela ditadura civilmilitar de 1964, como sabe-se, foi dirigido explicita e principalmente contra "subversivos" e "comunistas". Mas os fraudadores foram mais longe, eles também montaram um dispositivo de controle moral contra o comportamento sexual, considerado "desviante". Por exemplo, 
homossexuais, travestis, prostitutas e outros considerados "perversos" ou "anormais" foram sujeitos à perseguição, detenções arbitrárias civil e militar, expurgados do serviço publico, censurados e objeto de todas as formas de violência.

Com a pesada repressão sofrida, a comunidade LGBT responde criando e reforçando movimentos de resistência inspirados por organizações que lutam pelos direitos os gays no contexto internacional. No final da década de 1970, vários grupos começaram a se mobilizar e formar coletivos para lutar contra a opressão e o preconceito do Estado contra a população LGBT, a fim de defender seu reconhecimento e seus direitos. A perseguição de homossexuais durante a ditadura foi outro capítulo na história da violência contra pessoas e organizações LGBT. Portanto, sua luta ainda é necessária e atual no Brasil e no mundo.

Silva e Silva, (2002) aponta que até final da década de 1960 a Educação Sexual e questões relacionadas a essa temática eram fortemente reprimidas severamente pela Igreja Católica. Toda questão relacionada à sexualidade era passível de discriminação segundo a ótica religiosa, uma vez que tudo estava relacionado ao pecado e à fornicação. As escolas que resolviam trabalhar a Educação Sexual eram passíveis de terem seus diretores exonerados, seus professores e alunos expulsos. A inclusão da perspectiva de Educação Sexual nas Políticas Públicas ainda ocorre de forma lenta. Em 1968 a deputada do Estado do Rio de Janeiro, Júlia Steimbruck criou um Projeto de Lei cujo objetivo era estabelecer a obrigatoriedade da educação sexual nas escolas, fazendo então, a inter-relação entre sexualidade e educação. Sendo que em 1970 ainda tramitava no Congresso quando então, foi radicalmente descartado pelo parecer da Comissão Nacional de Moral e Civismo.

A partir da década de 1990 do século XX foram formuladas políticas para responder as questões referentes às desigualdades de gênero e de sexualidade. $\mathrm{O}$ Brasil sofreu pressão internacional para incluir essas temáticas nos documentos oficiais. As discussões sobre essas temáticas aqui no Brasil foram fundamentadas em alguns documentos internacionais, tais como, a Declaração Mundial sobre Educação para todos, ocorrida na Tailândia em 1990, o Projeto Educação para Todos (EPT), do Senegal em 2000, entre outros. O Brasil assinou todos os documentos países que têm liderado as questões relacionadas ao gênero e à sexualidade, assumindo o compromisso 
de dirimir as desigualdades e as discriminações no tocante a essas temáticas.

De acordo Figueiró (2006), a Sexualidade vai além da dimensão biológica: também é culturalmente determinada. Assim sendo, ao discutir sobre questões relacionadas a essa temática faz-se necessário que a escola provoque reflexões nos estudantes. Essas reflexões podem contribuir para o auto reconhecimento dos sujeitos e de sua sexualidade e como seres capazes de construir relacionamentos saudáveis e positivos. Dessa forma, esses jovens também podem intervir no curso de suas vidas e participar de transformações do ambiente sociocultural.

Dessa forma, a Educação Sexual pode ajudar os adolescentes a reflorescer o erotismo e o gênero. Primeiro está considerado a sexualidade com algo bom, belo e importante na vida das pessoas, o segundo, considera homens e mulheres iguais em todas as áreas, isto é equidade entre os sexos.

Diante do exposto, observamos a Educação Sexual formal brasileira ainda esta em construção, durante um bom tempo esteve presente sob a forma de um currículo oculto, em outros momentos sob a tutela e a voz do discurso autoritário advindos de uma perspectiva médica e biológica, silenciando ou não levando em consideração a diversidade sexual.

Pode-se notar que a educação sexual emancipatória se faz nas margens, em atividades tímidas, ações de pequeno porte, uma vez que ainda é muito complexa a aceitação da prática discursiva da sexualidade fora do discurso biologizante.

\section{OS ESPAÇOS ESCOLARES E SUAS REPRESENTAÇÕES ACERCA DAS SEXUALIDADES E DOS GÊNEROS}

Para Furlani, (2008, p. 307) na escola, e em outros espaços as identidades sexuais e de gênero estão sendo constantemente produzidas. As instituições públicas e as mais diversas mídias também estão penetradas e produzem representações acerca das sexualidades e dos gêneros. A escola funciona em todos os momentos com aspectos mais conservadores e morais da sociedade, bem como com suas vanguardas transgressoras. Precisamente por causa da existência de um universo quase infinito de discursos sobre sexualidade humana, alguns dos quais são dotados de forças mais ou menos poderosas, certos temas e abordagens em detrimento do silencio alheio são preferidos, 
na prática pedagógica, as instruções biológicas parecem se aplicar a questões relacionadas à sexualidade.

Ao analisarmos a Lei de Diretrizes e Bases da Educação Nacional 5.692/71, podemos perceber a ausência de uma regulamentação sobre a Educação Sexual. Portanto, a instituição nacional da Educação Sexual ocorreu somente com a Lei de Diretrizes e Bases da Educação 9.394/96. 201. Com relação à forma com que comumente tem ocorrido a Educação Sexual no ambiente escolar, Furlani (2008, p. 287), aborda que é possível pensar nela como um campo de conhecimento em que, historicamente, tem prevalecido o conveniente silenciamento, a estratégica restrição temática, o privilegiamento do senso comum, a manutenção do preconceito e da intolerância, a possível falta de preparo pedagógico das (os) educadoras (es) e o sutil descaso por parte da Escola e das políticas educacionais.

A educação sexual na vida escolar é marcada por relações de poder e controle sobre as atividades realizadas, bem como o desenvolvimento sexual das pessoas, portanto o sujeito normativo é constituído como sujeito. No entanto, podemos considerar que os mecanismos discursivos referentes à sexualidade de crianças e adolescentes atuam de um lado, indireta e imprecisamente, de outro, de maneira normativa e castrada. De acordo o filósofo Michel Foucault (1988) em sua obra A história da Sexualidade, o próprio processo de negação da sexualidade das crianças se configura como uma forma de interdição. Silenciar a sexualidade infantil seria um indício desse processo de negação, porque algo que não é concebido como existente, torna-se relegado ao reino do indizível do inconcebível.

Foucault (1988, p. 10), as crianças, por exemplo, sabe-se muito bem que não têm sexo: boa razão para interditá-lo, razão para proibilas de falar dele, razão para fechar os olhos e tapar os ouvidos onde quer que venham a manifestá-lo, razão para impor um silêncio geral e aplicado".

Desse ponto de vista podemos afirmar que o contexto de desenvolvimento do campo científico das ciências da saúde foi preponderante, de modo que a sexualidade infantil e juvenil foi enfim considerada de maneira discursiva.

Conforme afirma Foucault, (1988, p. 202), teriam sido as pesquisas realizadas por Freud que teriam possibilitado a visibilidade sobre a sexualidade em todas as fases da vida, inclusive na fase infantil. 
Dessa forma, embora a sexualidade adolescente estivesse sendo reconhecida, a partir da configuração discursiva dos indivíduos dessa faixa etária como sujeitos de desejo, o autor ainda aborda que isso não implica que a liberdade seja atribuída a experiências e práticas sexuais, pelo contrário. A concepção da existência da sexualidade na infância e a adolescência implicou e ainda implica a formulação de diversas estratégias para normalizar e controlar a sexualidade e a vida dos indivíduos. Acima de tudo, o discurso médico higienista tornou-se a chave para tornar tal tópico acessível.

Portanto, a sexualidade das novas gerações passou a ser regulamentada e proibida por meio de mecanismos discursivos relacionados à saúde e à higiene. Mas como esses mecanismos discursivos foram transmutados em práticas sociais. Em outras palavras, como sua subjetivação ocorre pelo processo de institucionalização do sexo fundamental nesse aspecto, sendo a escola o ambiente propício para a propagação desse conjunto de saberes.

Para Revel e Petter (1995, p. 144), a doença é quase sempre um elemento de desorganização e de reorganização social: a esse respeito ela torna frequentemente mais visíveis articulações essenciais do grupo, as linhas de força e as tensões que os traspassam. O acontecimento mórbido pode, pois, ser o lugar privilegiado de onde melhor observar a significação real de mecanismos administrativos ou das práticas religiosas, as relações entre poderes, ou a imagem que uma sociedade tem de si mesma.

É importante ressaltar que qualquer construção discursiva visa influenciar a configuração das práticas sociais. Portanto, os mais diversos discursos são desenvolvidos com a intenção de manipular e atuar na realidade, mesmo que o seu escopo esteja implícito. Com relação ao poder de certos discursos e sua capacidade de instituir conhecimentos e práticas, fica claro que o comportamento sexual foi finalmente regulado, como critério para o estabelecimento de comportamentos julgados corretos ou errôneos pensamento médicohigienista. Havia, portanto, uma ligação direta entre atividade sexual e saúde.

Nesse sentido a luta contra a masturbação, a higiene corporal, a prevenção da gravidez precoce e o combate às infecções sexualmente transmissíveis estão presentes desde a introdução da educação sexual nas escolas brasileiras. 
A existência da Educação Sexual formal até a inserção dos temas transversais assentava-se numa prática discursiva normatizada pelo discurso jurídico, médico e biológico, que eram o lócus de onde se podia discursar sobre a sexualidade, pois ali se encontravam o que poderia e deveria ser ensinado sobre a sexualidade.

\section{CONSIDERAÇÕES FINAIS}

Não se toca em um fruto em broto e nem se faz abrir ou crescer à força e, principalmente, com mãos sujas. De fato, é importante ressaltar que, diante de um conjunto de condições históricas, as sociedades estabelecem o que pode ser abordado nas áreas da educação sexual. Portanto, os sujeitos tratados ou silenciados são indicativos de problemas que são resolvidos socialmente como o discurso da escola permite. Deve-se considerar que o período de ditadura militar, assim como a resultante repressão e censura, também afetou o desenvolvimento de uma política pública que estabeleça os princípios básicos que regem a educação sexual no Brasil.

A ausência de práticas discursivas de regulamentação configurouse uma forma de interdição, sendo a educação sexual assentada em discursos moralizantes e biologizantes. O discurso da defesa da moral e dos bons costumes construíram nesse momento os saberes sobre/da sexualidade e o sujeito em torno de uma moral comum.

Nesse discurso fundador, houve a ausência de posicionamento de uma política de formação sexual escolar para a Educação Básica, que acabou por não gerar regulamentação nas escolas.

\section{REFERÊNCIAS}

BRASIL. Ministério da Educação. Lei de Diretrizes e Bases da Educação Nacional. LEI No 5.692, de 11 de agosto de 1971. Disponível em: www.planalto.gov.br/ccivil_03/leis/ I5692.htm. Acesso em: 10 ago. 2019.

BRASIL. Ministério da Educação. Lei de Diretrizes e Bases da Educação Nacional, 1996. Disponível em: http://portal.mec.gov.br/arquivos/pdf/idb.pdf. Acesso em: 10 ago. 2019.

BRASIL. Ministério da Educação. Parâmetros Curriculares Nacionais: Orientação Sexual, 1998. Disponível em: http://portal.mec.gov.br/seb/arquivos/pdf/livro102.pdf. Acesso em: 10 ago. 2019.

BRASIL. Diário do Congresso Nacional. Seção I, Suplemento ao $n^{\circ} 21$, Câmara dos deputados. Capital Federal: 15 de fevereiro de 1968. Disponível em: www.camara.gov. br. Acesso em: 10 ago. 2019.

CÉSAR, M. R. A. Gênero e sexualidade na escola: produzindo corpos, narrativas e significados. Fazendo Gênero 8 - Corpo, Violência e Poder: Florianópolis, 2008. 
COLLING, A. M. 50 anos da Ditadura no Brasil: questões feministas e de gênero. Opsis, v. 15, n. 2, 2015. Disponível em: https://www.revistas.ufg.br/Opsis/article/view/33836. Acesso em: 30 jul. 2019.

FOUCAULT, M. História 3: o cuidado de si. 12. ed. Rio de Janeiro: Graal, 1997. 235p. FOUCAUT, M. História da sexualidade. Vol. 1 - A vontade de saber. 13. ed. Rio de Janeiro: Graal, 1988.

FOUCAULT, M. A Ordem do Discurso. Aula inaugural no College de France. Pronunciada em 2 de dezembro de 1970. Tradução de Laura Fraga de Almeida Sampaio. São Paulo: Loyola: 1996, p. 8.

FOUCAULT, M. História da sexualidade. Vol.2 - O uso dos prazeres. 8. ed. Rio de Janeiro: Graal, 1984.

FURLANI, J. Educação Sexual: quando a articulação de múltiplos discursos possibilita sua inclusão curricular. Perspectiva, Florianópolis, v. 26, n. 1, 283-317, jan./jun. 2008.

KEHL, R. O problema da educação sexual: Importância eugênica, falsa compreensão e preconceitos - como, quando e por quem deve ser ela ministrada. In: COSTA, M. J. F. F. (org.). Conferência Nacional de Educação. Brasília: INEP, 1997. p. 433-437.

GUIMARÃES, I. Educação sexual na escola: mito e realidade. São Paulo: Mercado de Letras, 1995.

GREEN N, J. Ditadura e homossexualidades repressão, resistência e busca da verdade, 2015.

OLIVEIRA, I. B. et al. A ordem antes do progresso: o discurso médico higienista e a educação dos corpos no Brasil no início do século XX. Fênix - Revista de História e Estudos Culturais, v. 9, Ano IX, $\mathrm{n}^{\circ} 1 \mathrm{I}$.

PADILHA, C. Sobre a educação sexual. In: COSTA, M. J. F. F. (Org.). Conferência Nacional de Educação. Brasília: INEP, 1997. p. 428 - 433. Quisa / n²6. Fundação Carlos Chagas, 1977.

PARANÁ. Diretrizes Curriculares de Gênero e Diversidade Sexual da Secretaria de Estado da Educação do Paraná. Versão Preliminar, Curitiba: 2010. Disponível em: www.diaadia. pr.gov.br. Acesso em: 01 ago. 2019.

PRIORE, M. D. Histórias íntimas: sexualidade e erotismo na história do Brasil. São Paulo: Editora Planeta do Brasil, 2011.

REVEL, J.; PETER, J. P. O Corpo - o homem doente e sua história. 1995.

NORA, P. História: novos objetos. 4. ed. Rio de Janeiro: Francisco Alves, 1995.

ROSEMBERG, F. Educação sexual na escola. Cad. Pesq., (53), Fundação Carlos Chagas, 1985.

VEIGA-NETO, A. Foucault e a educação. 2. ed. Belo Horizonte: Autêntica,2005.

Recebido em: 15/12/2019

Aceite em: 18/12/2019 